\title{
Video modelling and reducing anxiety related to dental injections - a randomised clinical trial
}

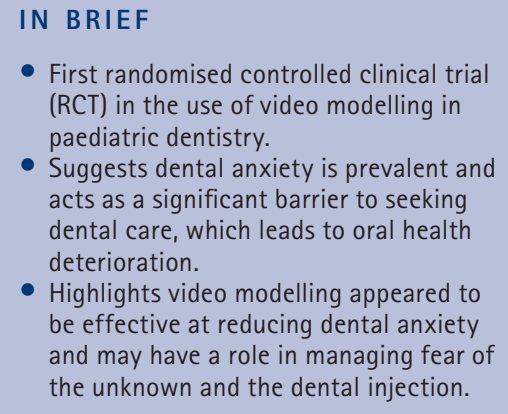

\author{
A. Al-Namankany, ${ }^{* 1}$ A. Petrie ${ }^{1}$ and P. Ashley ${ }^{3}$
}

VERIFIABLE CPD PAPER

Context This study was part of a successfully completed PhD and was presented at the IADR/AADR General Session (2013) in Seattle, Washington, USA. The report of this clinical trial conforms to the CONSORT statement. Objectives A randomised controlled trial to investigate if video modelling can influence a child's anxiety before the administration of local anaesthesia (LA). Method A sample of 180 (6- to12-year-old) children due to have dental treatments under LA were randomly allocated to the modelling video or the control video (oral hygiene instruction). The level of anxiety was recorded before and after watching the video on the Abeer Children Dental Anxiety Scale (ACDAS) and the child's ability to cope with the subsequent procedure was assessed on the visual analogue scale (VAS). A two group chi-square test was used as the basis for the sample size calculation; a significance level of 0.025 was chosen rather than the conventional 0.05 to avoid spurious results arising from multiple testing. Results Children in the test group had significantly less anxiety after watching the video than children in the control group throughout the subsequent dental procedure; in particular at the time of the LA administration ( $p$ <.001). Conclusion Video modelling appeared to be effective at reducing dental anxiety and has a significant impact on needle phobia in children.

\section{INTRODUCTION}

Anxiety is defined as a multi-system response to a supposed threat or danger. It comprises a combination of biochemical changes in the body and aspects of the patient's personal history, memory and the social situation. Anxiety may occur without cause, or it may be based on a real situation that leads to a reaction that is out of proportion to what would normally be expected. Severe anxiety can have a serious impact on daily life and effect quality of life and its different dimensions, such as speaking, eating and appearance, and through these also social intercourse. ${ }^{1}$

Dental anxiety is cumulative over time and its development is influenced by multiple variables. It is most likely to start in childhood. ${ }^{2}$ It is relatively common in the dental setting, affecting approximately $9 \%$ of children in normal populations in Australia, Canada, Europe, and America. The British National Children's Dental Health Survey found that the proportion of children who

\footnotetext{
'University College London, Eastman Dental Institute, London

*Correspondence to: Dr Abeer Al-Namankany

Email:a.alnamankany@yahoo.com
}

\section{Refereed Paper}

Accepted 16 December 2013

DOI: 10.1038/sj.bdj.2014.497

${ }^{\circledR}$ British Dental Journal 2014; 216: 675-679 were dentally anxious steadily increased through the primary school years and then levelled off during the secondary school years to about $50 \%$ of the population. ${ }^{3}$ Anxiety of dental injection is the most commonly reported reason for dental anxiety, followed by extraction and drilling tooth. ${ }^{4}$ It is usually associated with high caries rate and the need for oral rehabilitation. ${ }^{5}$ Indeed, several studies reported the strong relationship between dental anxiety and avoidance of dental care. ${ }^{6}$ This anxiety is a barrier to carrying out dental treatment safely and simply in the dental chair.

Dental anxiety can act as a major source of stress for general dental practitioners who treat the anxious patien. ${ }^{7}$ In this study, the anxious patient required approximately $20 \%$ more chair time than the low-anxious patient. $^{7}$ Moreover, dental anxiety could interfere with the efficiency of treatment by more frequent interruptions. Therefore, the management of anxiety is not only for the patient's sake, but for the potential economic impact on the business practice of dentistry. ${ }^{8}$

Video modelling is an effective tool for behaviour changing; it has been used in medicine, sport and other fields. It is used extensively with autistic children and children with anxiety. Video modelling could be effective for dental anxiety reduction. However, it is not commonly used in the dental practice and there is a lack of randomised controlled clinical trials in this area. ${ }^{9}$ To date, there is no randomised controlled clinical trial to investigate the effect of video modelling on the behaviour of anxious children receiving dental treatment. Therefore, the objective of this randomised controlled trial (RCT) was to investigate the effect of video modelling on the dental anxiety level of those children receiving dental treatment with local anaesthesia throughout the procedure. In particular, to investigate if video modelling can influence the patient's anxiety around administration of local anaesthesia.

The null hypothesis was that there was no difference between the modelling and the control groups in the change in dental anxiety scores of participants when video modelling was used to reduce anxiety for children having dental treatment with local anaesthesia.

\section{METHOD}

The trial design was a parallel randomised controlled trial. The ethical approval for the study was obtained from the Charing Cross Ethics Committee; Reference number: 08/ H0711/63. A statistically calculated sample size of 64 children was used. To allow for dropouts a total of 80 children were recruited, 40 in the test group and 40 in the control 
group. Two videos were used for this study, the modelling video that showed a dentist doing a dental filling under local anaesthesia for a 9-year-old girl; and the control oral hygiene instruction video with the same dentist and girl in a non-clinical sitting. Two information sheets were designed for parents or legal guardians and the child patient, respectively. Written consent was obtained from parents or those with legal responsibility for the child, and children were also asked for their verbal assent.

The inclusion criteria were: the availability of DVD facilities at home; children aged 6-12 years of age; healthy children with American Society of Anaesthesiologists ASA scale, class I and II; and children who were assessed to be dentally anxious based on the score of $\geq 26$ on ACDAS. The exclusion criteria were: children who did not meet the inclusion criteria; children with a learning disability; children who needed emergency dental treatment. The participants were randomly allocated into intervention (modelling video) and control groups with the aid of computer-generated random numbers by the statistician (AP); these were entered into sealed envelopes that were opened in sequence in accordance with patient participation. All participating children and the dentists providing dental treatment were blinded to the type of video. The chief investigator (AA) randomly allocated the participants to their groups (modelling or control).

\section{Study measures}

\section{ACDAS}

The Abeer Children Dental Anxiety Scale (ACDAS) was used to assess the dental anxiety scores on the first visit as a baseline score before watching the video..$^{10}$ It was also used on the second visit after watching the video and immediately before the start of the dental treatment. It could therefore be used to compare the dental anxiety scores before and after watching the videos.

\section{VAS}

The visual analogue scale (VAS) was used as a supplementary assessment tool on the second visit during treatment and throughout eight stages of the visit. VAS score was used as it is recommended to use more than one scale in any dental anxiety study ${ }^{11}$ and also because it would not have been practical to repeat the ACDAS index at regular intervals throughout treatment, whereas the child could just put a mark on the VAS. The VAS score was determined by measuring in millimetres from the left hand end of a $100 \mathrm{~mm}$ line to the point that the

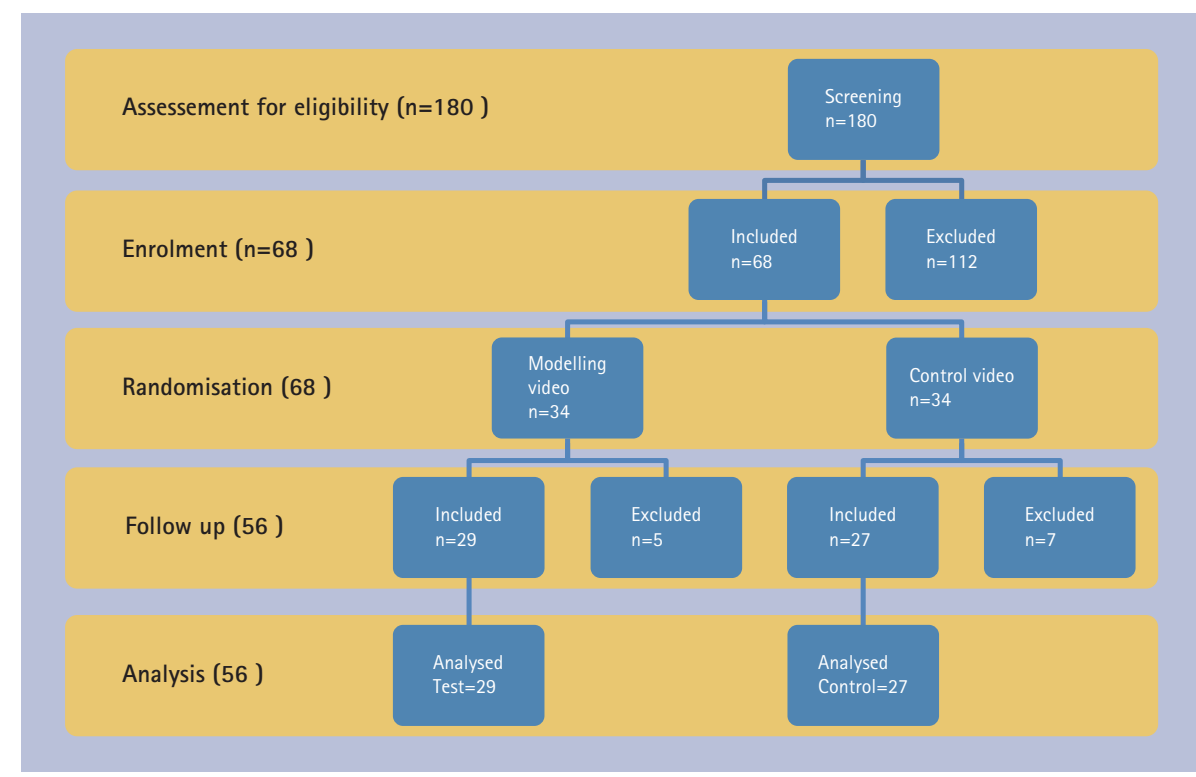

Fig. 1 The participant's flow chart throughout the RCT

Table 1 DA scores before and after watching the video

\begin{tabular}{|l|l|l|} 
& Modelling group & Control group \\
\hline Total score difference in two visits & $9.37, \mathrm{SD}=3.67$ & $-0.66, \mathrm{SD}=3.51$ \\
\hline LA score change in two visits & $19.2 \%$ showed no change & $80.8 \%$ showed no change \\
\hline
\end{tabular}

patient marked his or her response, where the extreme left side of the line indicated 'Not afraid at all' and the extreme right side indicated 'Very afraid'. The assessment stages were: VAS1: sitting in the waiting area; VAS2: entering the dental clinic; VAS3: sitting on the dental chair; VAS4: dental examination with mirror; VAS5: teeth polishing/fissure sealant; VAS6: local anaesthesia injection; VAS7: tooth drilling; and/or VAS8: tooth extraction.

\section{Study procedure}

The recruitment for the study started from October 2010 and continued until March 2011. The entire procedure was carried out by the chief investigator (AA) who attended the new patients' clinic daily for 6 months to introduce the project to the target group, gave them the information sheet, obtained the consent and assessed their anxiety on the ACDAS. The interviews took place in the Department of Paediatric dentistry and the School of Hygiene and Therapy at the Eastman Dental Hospital UCLH. On the first visit, the chief investigator enrolled those children meeting the inclusion criteria to the study and allocated them randomly to either the modelling or control groups. She then gave them the relevant video to watch at home, asked them to arrive 15 minutes earlier for their second visit and requested that they not tell any dental staff about which video they had watched.
On the second visit, the chief investigator met each of the participants and displayed the relevant video to each child on the computer of the main clinic during break hours or in her office. She then asked the child to report his/her anxiety on the ACDAS and the parents or legal guardian to complete the feedback questionnaire immediately before the child entered the dental clinic. The child also reported his/her dental anxiety on the VAS throughout the dental treatment visit.

\section{Data analysis}

A histogram was drawn to show the distribution of age by gender and groups (test/control). The mean, standard deviation (SD) and the 95\% confidence interval (CI) of the mean were evaluated for age in each video group. The total scores for the dental part of the ACDAS can range from (13 to 39) with a cut-off point of $>26$ to indicate anxiety. The baseline ACDAS score in the first visit, before watching the video, for all participants was $>26$. The total ACDAS was measured for each patient at each visit and the difference in the scores between the first and the second visit was measured by subtracting the score of visit 2 from the score of visit 1 . The mean, SD and the $95 \%$ CI of the mean were measured for the difference of the ACDAS total for test and control groups, and the difference was plotted on a histogram for each group. In order to compare the mean difference from the first 


\begin{tabular}{|c|c|c|c|c|}
\hline VAS stages & Modelling group & Control group & $P$ value & Difference in means \\
\hline In the waiting room & $\begin{array}{l}\text { Mean } 7.05 \\
\text { SD } 19.64\end{array}$ & $\begin{array}{l}\text { Mean } 15.97 \\
\text { SD } 22.17\end{array}$ & 0.12 & $\begin{array}{l}-8.9(95 \% \mathrm{Cl}-20.17 \\
\text { to } 2.34)\end{array}$ \\
\hline Entering the dental clinic & $\begin{array}{l}\text { Mean was } 22.88 \text {, } \\
S D=26.5\end{array}$ & $\begin{array}{l}\text { Mean } 33.25 \\
\text { SD } 25.21\end{array}$ & 0.14 & $\begin{array}{l}-10.37(95 \% \mathrm{Cl} \\
-24.23 \text { to } 3.48 \text { ) }\end{array}$ \\
\hline Sitting on the dental chair & $\begin{array}{l}\text { Mean } 13.39 \\
\text { SD } 15.45\end{array}$ & $\begin{array}{l}\text { Mean } 31.6 \\
\text { SD } 24.73\end{array}$ & 0.002 & $\begin{array}{l}-18.21(95 \% \mathrm{Cl} \\
-29.35 \text { to }-7.06)\end{array}$ \\
\hline Examination with mirror & $\begin{array}{l}\text { Mean } 9.59 \\
\text { SD } 14.71\end{array}$ & $\begin{array}{l}\text { Mean } 36.51 \\
\text { SD } 25.09\end{array}$ & $p<0.001$ & $\begin{array}{l}-26.92(95 \% \mathrm{Cl} \\
-38.05 \text { to }-15.8)\end{array}$ \\
\hline Fissure sealant/prophylaxis & $\begin{array}{l}\text { Mean13.95 } \\
\text { SD } 15.24\end{array}$ & $\begin{array}{l}\text { Mean } 67.4 \\
\text { SD } 24.4\end{array}$ & $p<0.001$ & $\begin{array}{l}-53.45(95 \% \mathrm{Cl} \\
-70.75 \text { to }-36.14)\end{array}$ \\
\hline Local anaesthesia & $\begin{array}{l}\text { Mean } 23.12 \\
\text { SD } 26.70\end{array}$ & $\begin{array}{l}\text { Mean } 86.55 \\
\text { SD } 21.43\end{array}$ & $p<0.001$ & $\begin{array}{l}-63.42(95 \% \mathrm{Cl} \\
-76.71 \text { to }-50.13)\end{array}$ \\
\hline Tooth drilling & $\begin{array}{l}\text { Mean } 25.38 \\
\text { SD } 25.66\end{array}$ & $\begin{array}{l}\text { Mean } 79.04 \\
\text { SD } 25.37\end{array}$ & $p<0.001$ & $\begin{array}{l}-53.67(95 \% \mathrm{Cl} \\
-69.79 \text { to }-37.54)\end{array}$ \\
\hline Tooth extraction & $\begin{array}{l}\text { Mean } 36.53 \\
\text { SD } 33.52\end{array}$ & $\begin{array}{l}\text { Mean } 95.28 \\
\text { SD12.18 }\end{array}$ & $p=0.006$ & $\begin{array}{l}-58.75(95 \% \mathrm{Cl} \\
-84.8 \text { to }-32.7)\end{array}$ \\
\hline
\end{tabular}

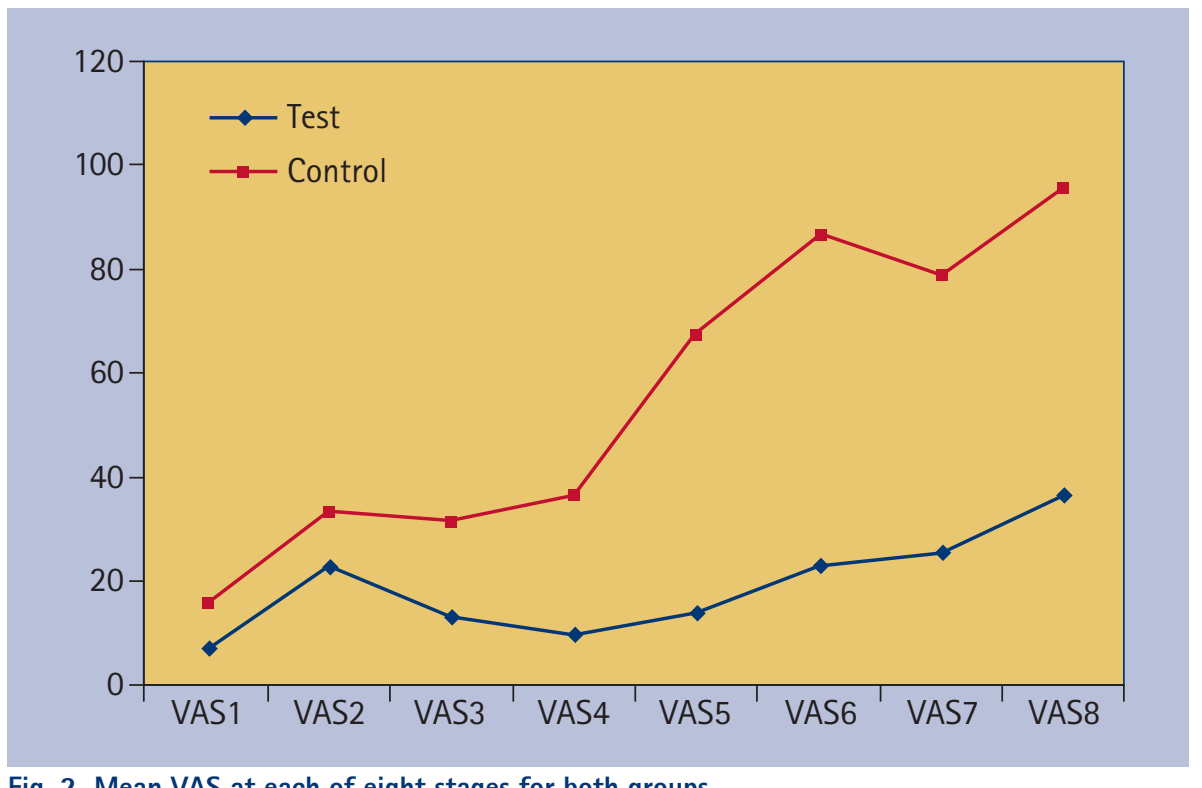

Fig. 2 Mean VAS at each of eight stages for both groups

to second visit in the total ACDAS dental anxiety score between the test and control groups, a two-sample $t$-test was used.

A two-sample $t$-test was used in order to compare the VAS score (expressed as a percentage) between test and control groups for each of the clinical stages, The mean, SD and the $95 \% \mathrm{CI}$ of the mean were evaluated for the difference of the VAS for test and control groups and the difference was plotted on a histogram for each group.

\section{Study outcomes}

The primary outcome for this study was the change in the score of dental anxiety on the ACDAS scale from the first to the second visit.

The secondary outcome were the scores of the dental anxiety on the VAS of local anaesthesia (LA) application, and the responses of the parent/legal guardian to assess if video modelling could be used as or the control video $(\mathrm{n}=34)$. On the second visit, five children from the modelling group were excluded, three failed to watch the video, two dropped out; and seven children from the control group were excluded (dropped out), but children who failed to watch the video from the control group were not excluded. Fifty-six children (29 modelling, 27 controls) had their results analysed. The flow chart of the participants is shown in Figure 1. For both video groups, age was approximately normally distributed, the minimum age was 6 years and the maximum age was 12 years. For the test group, the mean age was 9.15 years, median $=9$ years, $\mathrm{SD}=2.75$ years and the $95 \% \mathrm{CI}$ of the mean was 8.06 to 10.24 years. For the control group, the mean age was 9.07 years, median $=9$ years, $\mathrm{SD}=2.47$ years and the 95\% CI of the mean was 8.13 to 10.01 years. The male and female participants were approximately equally distributed in the two groups: 50\% (11 out of 27) of the test group were males, and 50\% (11 out of 29) of the control group were males.

\section{Video modelling and dental anxiety scores}

The total scores for the dental part of the ACDAS had a possible range of 13 to 39 . The mean of the difference between the first visit 'before watching the video' and the second visit 'after watching the video' was calculated. There was a significant difference in the change in ACDAS score from the first to second visit between the test and control groups for the response on question 6 on ACDAS: 'How do you feel about having a pinch feeling in your gum?' ( $p<0.001)$, where the responses at each visit were coded one, two and three for 'happy', 'OK' and 'scared', respectively. The results for both groups are presented in Table 1.

alternative method to general anaesthesia for routine dental treatment of children with dental anxiety.

\section{RESULTS}

\section{Demographic}

In order to assess the participant's eligibility, 180 children (6-12 years) were approached by the chief investigator and 112 children were excluded on the first visit for the following reasons:

- The child was referred to GA $(88.3 \%$, $\mathrm{n}=99$ )

- The parent or caregiver refused to participate $(3.6 \%, \mathrm{n}=4)$

- Did not met the inclusion criteria (8\%, $\mathrm{n}=9$ ).

On the first visit, 68 children were randomised to the modelling video $(\mathrm{n}=34)$

\section{Dental anxiety scores on VAS}

The score of dental anxiety (DA) was reported by each child throughout the dental treatment stages and the data is summarised in Table 2. The summary of the VAS scores throughout the eight clinical stages for test and control groups in the behaviour management trial is shown in Figure 2, where the $\mathrm{X}$ axis represents the treatment stages and the $\mathrm{Y}$ axis represents the VAS scores.

\section{Feedback of the parents/legal guardians}

In the feedback for the question 'In order to have a risk-free dental treatment, do you prefer to choose the drug free behaviour management methods for the anxiety of your child or the treatment in the operation room under general anaesthesia? Why 
please?', only one mother chose the general anaesthesia (GA) method and the reason was her busy schedule meant it was inconvenient to bring her child for dental treatment over several visits, whereas $98.3 \%$ chose the video modelling (drug free) methods for the following reasons:

'It is safer and better for my child/my child is too young to have the GA experience/it is a risk free method/my child is worried about the GA/I cannot stay with my child during the treatment under GA/apart from being safe, the video helps my child to get rid of the dentist phobia/the recovery is faster than GA/it builds confidence so my child can go to the dentist without being worried/GA will not help my child with his confidence to go to dentist/giving my child drugs without real necessity is against what I feel is good for my child/the video helps my child with his fear/ the video is best for the child and the NHS/ the child's needs is the priority/drug free to relieve anxiety and GA to relieve pain and discomfort/drug free for minor treatment and GA for the major ones.'

\section{DISCUSSION}

Although there were attempts to investigate the effect of video modelling on dental anxiety by previous studies, ${ }^{12-14}$ to date there is no RCT to investigate the effect of video modelling on the behaviour of anxious children receiving dental treatment. Therefore, this study is the first RCT for the use of video modelling in paediatric dentistry. Appropriate numbers, as determined by statistical evaluation, were collected in both study groups ensuring that the optimal sample size was achieved. Therefore results from this study can be treated with some confidence. This study was limited to children aged 6 years and over as they were likely to have the cognitive ability to self-report their anxiety. Future work might also look at the use of modelling videos for younger children, even if they are just to prepare them for a simple examination at the dentist.

To minimise potential bias in data collection, it is strongly recommended that the person gathering the study data and the clinician treating the patient should not be the same person. ${ }^{15}$ Therefore, an independent operator performed the clinical treatment. The data collection was completed by the chief investigator (AA).

In general, the test group was more successful at treating dental anxiety and at alleviating fear of the unknown $(\mathrm{p}<0.001)$ than the control group, presumably because the test group were aware of what was going to happen to them after watching the modelling video. In the response to the key question (question 6 of ACDAS: How do you feel about having a pinch feeling in your gum?), 19.2\% of the test group and $80.8 \%$ of the control group showed no change in the response for local anaesthesia after watching the modelling video. On the VAS, this difference was also significant between modelling and control groups ( $p$ <0.001). Hence, the video modelling was able to decrease the anxiety scores at the time of LA applications for the modelling group.

Generally, there was a significant difference between modelling and control groups in the mean VAS throughout the rest of the dental treatment $(P<0.001)$. In the waiting room, the dental anxiety for both groups was very low, perhaps because the Eastman Dental Hospital (EDH) has a very child friendly waiting area with many activities and entertainments for children. The level of DA was slightly raised when the child entered the dental clinic from the waiting room, although there was no significant difference in the mean VAS between the modelling and control groups $(p=0.14)$. When the child sat on the dental chair the DA level seemed to decrease on average and to be even less at the time of the dental examination with the mirror.

The percentage of the GA referral was very high being $88.3 \%$ for the children who were eligible to participate in this study. The video modelling method was chosen over the GA if this was possible by $98.3 \%$ of the participants. Clearly patients and their caregivers would like to avoid GA if possible; however, it was outside the scope of this study to look at reasons for selection of GA. Obviously, however, alternatives to GA should always be offered wherever possible.

The recruitment for this study was difficult at times as staff within the department would refer patients for GA frequently. In the absence of rigid criteria for referral to GA this is something that perhaps should be the subject of future research.

The aim of the study was to investigate if the use of the video would decrease anxiety surrounding delivery of local anaesthesia. Again while it was clear that use of the video reduced anxiety surrounding LA, it was difficult to show if it would increase uptake. Furthermore while all the children were planned for LA, not all of them had LA in the end. This was based on the operator's decision at the time. It was decided in the end to include these patients, as their anxiety surrounding this procedure was important information. Again further work is required to determine if use of the video will help with this, also it is needed to determine if anxiety over dental treatment following this procedure is likely to decrease as a result of the modelling video intervention.

A previously published systematic review found that the quality of reporting of clinical trials was poor and often not adequate to allow readers to assess trial validity. ${ }^{16}$ Therefore, the reporting of this clinical trial conforms to the CONSORT statement.

The limitation of this study was that the child in the video was not similar in terms of age, gender and ethnic background to every patient in the study; the possibility of the effect of these factors on the modelling outcomes is recommended for future research. In addition, modelling the child's demographic was not feasible in terms of practicalities and costs. Furthermore, it was not feasible to provide a video model for every different dental treatment; the idea of the video was to give the child a general idea about the basics and the most commonly used procedures in the dental clinic.

In general, participants felt that the video was of a high quality. This is not surprising given that it was produced by a professional company at some expense. What we could not quantify was how important video quality was in terms of obtaining valid and useful results. This could be the subject of future research.

\section{CONCLUSIONS}

Video modelling is an effective method to decrease dental anxiety, especially for local anaesthesia applications.

Thank you to all staff at University College Londonthe Eastman Dental Institute, especially Ms Doreen Matthew who was the operating dentist in this study and Mr Javed Khanzada for his sincere IT help. This study was started at King's College London but for unfortunate reasons we had to move it to UCL. We would like to thank all the staff at KCL who were supportive in this study, especially Professor Tim Newton.

1. Luoto A, Lahti S, Nevanperä T, Tolvanen M, Locker D. Oral-health-related quality of life among children with and without dental fear. Int J Paediatr Dent 2008; 19: 115-120.

2. Tickle $M$, Jones $C$, Buchannan $K$, Milsom $K$, Blinkhorn A S, Humphris G M. A prospective study of dental. anxiety in a cohort of children followed from 5 to 9 years of age. Int J Paediatr Dent 2009; 19: 225-232.

3. Todd J E, Lader D. Adult dental health 1988 - report. London: Office of Population Censuses and Surveys London, 1991.

4. Bedi R, Sutclife P, Donnan P T, McConnachie J. The prevalence of dental anxiety in a group of 13-and 14-year-old Scottish children. Int J Paediatr Dent 1992; 2: 17-24.

5. Eitner S, Wichann M, Paulsent A, Holst M. Dental anxiety- an epidemiological study on its clinical correlation and effects on oral health. J Oral Rehabil 2006; 33: 588-593.

6. Arnrup K, Broberg A G, Berggren U, Bodin L. Treatment outcome in subgroups of uncooperative child dental patients: an exploratory study. Int J Paediatr Dent 2003; 13: 304-319.

7. Girdler N M, Hill C. Clinical sedation in dentistry. Chichester: Wiley, 2009.

8. Ayer W. Psychology and dentistry: mental health aspects of patient care. Haworth Press Inc, 2005. 
9. Wright FA, Giebartowski J E, McMurray N E. A national survey of dentists' management of children with anxiety or behaviour problems. Aust Dent J 1991; 36: 378-383.

10. Al-Namankany A, Ashley P, Fawcett C, Petire A The development of a Dental Anxiety Scale with a Cognitive component for Children and Adolescents. Paediatr Dent 2012; 34: 219-224.

11. Melamed B G. Methodological needs and behavioural research with child dental patients.
Anesth Prog 1986; 33: 34-40.

12. Melamed B G, Yurcheson R, Fleece E L, Hutcherson $S$ Hawes R. Effects of film modeling on the reduction of anxiety-related behaviours in individuals varying in level of previous experience in the stress situation. $J$ Consult Clin Psychol 1978; 46: 1357-1367.

13. Melamed B G, Weinstein D, Katin-Borland M, Hawes R. Reduction of fear-related dental management problems with use of filmed modeling. J Am Dent Assoc 1975; 90: 822-826.
14. Thelen M H, Fry R A, Fehrenbach P A, Frautschi N M Therapeutic videotape and film modeling: a review. Psychol Bull 1979; 86: 701-720.

15. Streiner D, Norman G. Health measurements scales a practical guide to their development and use. 4th ed. Oxford: Oxford University Press, 2008.

16. Al-Namankany A, Ashley P, Moles D, Parekh S.

Assessment the quality of reporting of Randomised Clinical Trials in paediatric dentistry. Int J Paediatr Dent 2009; 19: 318-324. 